\section{El CAS amplía las formas de difusión del patrimonio arqueológico sumergido a través de las nuevas tecnologías}

En los últimos años, el Centro de Arqueología Subacuática del IAPH ha realizado el esfuerzo de idear productos y actividades para la difusión del patrimonio arqueológico sumergido y el fomento de actitudes para su defensa y disfrute. El apoyo recibido en el año 2009 por parte del Ministerio de Ciencia e Innovación, a través de la Fundación Española para la Ciencia y la Tecnología (FECYT), y la reforma de la web del IAPH han venido a dar una mayor visibilidad a estos productos, permitiendo su consulta y descarga.
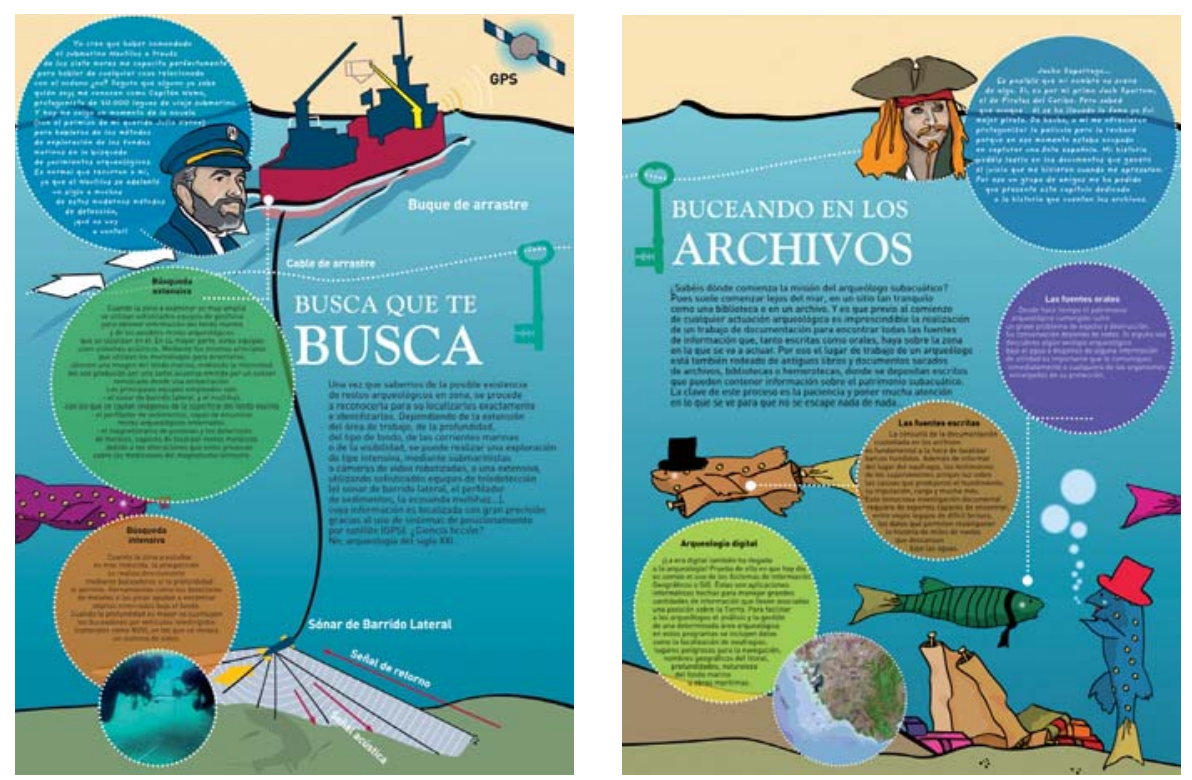

Carteles didácticos. Pósteres 3 y 4

El patrimonio arqueológico subacuático conforma una de las tipologías culturales de mayor atractivo para la sociedad. El carácter misterioso y aventurero que rodea a lo relacionado con el fondo del mar, asociado a la belleza y plasticidad de las imágenes captadas en este ambiente, son factores que juegan a su favor. Pero no todo es positivo. Si la mayor parte de la sociedad entiende que los yacimientos arqueológicos terrestres deben ser protegidos y preservados como parte que son de nuestro patrimonio cultural, su percepción cambia al referirse a los subacuáticos. Es frecuente en determinados colectivos (buceadores, pescadores, aficionados a la arqueología y expoliadores) referirse al patrimonio resultados no serán apreciables hasta medio plazo. Por ello, desde el primer momento, el IAPH tuvo claro que una de las líneas de trabajo del Centro de Arqueología Subacuática (CAS) debía ser la difusión encaminada a enseñar el método y las técnicas de trabajo utilizadas para su estudio y conservación; mostrar la labor que el propio Centro realiza en el marco de sus competencias y proyectos; y sensibilizar a la sociedad sobre la necesidad de mantener un uso respetuoso con el mismo, adoptando medidas para garantizar su preservación.

Desde entonces el CAS ha generado productos diversos (exposiciones, conferencias, comunicaciones en prensa, folletos, publicaciones, productos web, visitas guiadas y jornadas de puertas abiertas, etc.) destinados tanto al público general como, de manera especial, al colectivo educativo por entender que ésta es una "inversión cultural" de alta rentabilidad a medio plazo.

El apoyo recibido en el año 2009 por parte del Ministerio de Ciencia e Innovación, a través de la Fundación Española para la Ciencia y la Tecnología (FECYT), potenció la capacidad de acción en este campo. Ahora, la reforma de la web del IAPH ha venido a dar una mayor visibilidad a estos productos, permitiendo su consulta $y$, en muchos casos la descarga, a través tanto de la sección Sumérgete del canal Arqueología Subacuática como de la Zona Didáctica ubicada en la página principal de dicha web (www.iaph.es).

De esta forma, el proyecto FECYT ofreció la posibilidad de solventar la limitación que imponía la necesidad de desplazamiento creándose productos encaminados a llevar la arqueología subacuática fuera de las instalaciones del CAS. Este proyecto ha generado como materiales didácticos: una exposición en paneles portables y el cuaderno didáctico Matarile, diseñados para que pudiesen ser consultados y des- 
cargados en distintos formatos y calidad, además de una aplicación multimedia.

Los carteles didácticos (en total 9) se elaboraron en formato pdf y tamaño DIN A0 con la idea de que se puedan descargar en los centros educativos para su presentación en forma de exposición didáctica. Por su parte el cuaderno didáctico se ideó como un pequeño producto editorial elaborado de manera amena y atractiva, en el que se recopilan pequeñas noticias y anécdotas en torno a la arqueología subacuática y que, al igual que los carteles, pueden ser descargados por capítulos en formato pdf.

Además, pensando en el público en general, se creó una aplicación multimedia que, a manera de exposición virtual, muestra la metodología científica y técnicas empleadas en arqueología subacuática, así como los procesos que influyen en el deterioro de los elementos y materiales que conforman el patrimonio arqueológico subacuático. Diseñada en el marco del proyecto financiado por la FECYT, se basa en una interfaz gráfica y textual estructurada en base a 5 niveles de información por los que se navega de manera intuitiva. Cada uno atiende a una de las fases en las que se estructura el proceso científico de investigación en la arqueología subacuática (documentación, prospección, excavación, conservación e interpretación) permitiendo al usuario conocer los pormenores acerca de las técnicas y herramientas empleadas en ese campo.

Con estos últimos productos y actividades, el CAS ha demostrado su capacidad de adaptación y aprovechamiento de las herramientas tecnológicas para el fomento de la difusión, uno de sus objetivos principales. Su trayectoria asi lo atestigua. Desde su creación en 1998, ha trabajado en cuatro exposiciones temáticas: El CAS, un proyecto de futuro (en 1998), cuya finalidad era presentar el proyecto del Centro y la rehabilitación del edificio donde tiene
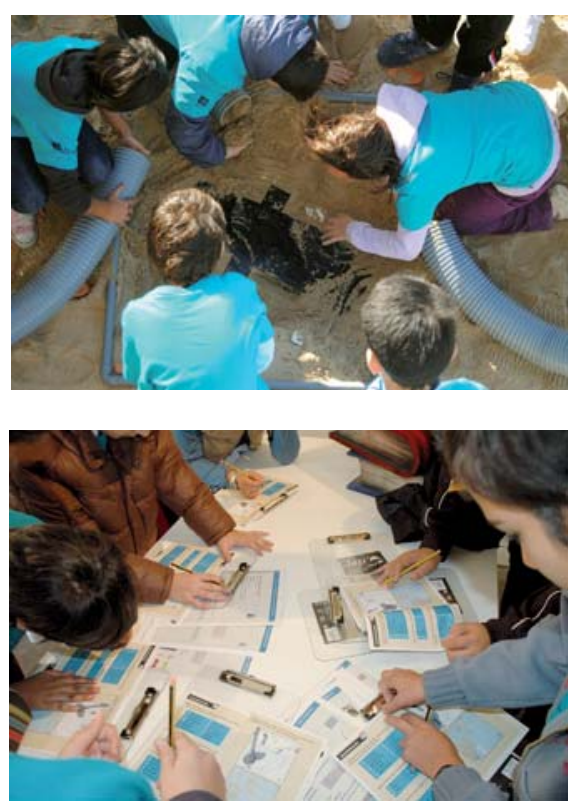

Taller didáctico. Alumnos participando en la fase de excavación y documentación. Fotos: Fondo Gráfico IAPH-CAS (Milagrosa Jiménez Melero)

\section{La reforma de la web del}

IAPH ha venido a dar una

mayor visibilidad a estos

productos a través tanto

de la sección Sumérgete

del canal Arqueología

Subacuática como de la

Zona Didáctica ubicada en

la página principal

su sede, el histórico balneario de Nuestra Señora de la Palma y el Real, ubicado en la playa de la Caleta de Cádiz; La restauración de las cerámicas de la Ballenera (Algeciras, Cádiz) (en 2002); en 2005, la exposición Trafalgar, en el marco de los actos organizados para la conmemoración del bicentenario del combate naval; Historias bajo el mar (2008) encaminada a narrar, mediante recursos diferentes, la apasionante historia que se encierra tras algunos de los innumerables naufragios históricos que duermen bajo las aguas del litoral andaluz.

Pero una de las labores más demandadas y valoradas a lo largo de los últimos años ha sido el programa de visitas guiadas al
CAS destinado a mostrar sus instalaciones y dar a conocer el trabajo que realizan sus técnicos. Ofertada como servicio público, el CAS del IAPH atiende desde hace más de una década de manera gratuita las demandas de visitantes $y_{1}$ principalmente, centros educativos: desde la educación primaria hasta la universitaria. Guiadas por una técnico y organizadas en grupo (mínimo de 10 personas y máximo de 25), durante un recorrido de aproximadamente hora y media se explica el proceso de estudio e investigación arqueológica y restauración de los bienes muebles de procedencia subacuática. La magnífica acogida del servicio en el colectivo educativo y su elevada demanda, principalmente desde el sector de la ESO, vino a plantear la posibilidad de crear una serie de talleres didácticos específicos para este tipo de usuario. El apoyo de la FECYT y la colaboración de la empresa de dinamización sociocultural Animarte lo hicieron posible. Con esta estrategia didáctica se pretende que alumnos del $2^{\circ}$ ciclo de Educación Primaria y $1^{\circ}$ ciclo de Educación Secundaria Obligatoria conozcan y participen en una simulación metodológica de una excavación arqueológica subacuática, utilizando técnicas adaptadas respecto a las que se emplean en esta disciplina. Por medio de diversos materiales didácticos y de la simulación de un yacimiento arqueológico subacuático en la arena de la playa, los alumnos conocen el proceso de trabajo de los arqueólogos en el medio subacuático, dibujando, fotografiando, excavando y restaurando un objeto previamente enterrado en la arena. La introducción de personajes (arqueólogo, pescadores y buceador) sirve para fomentar considerablemente la dinamización de la actividad, favoreciendo el aprendizaje y la actitud de compromiso para con la preservación del patrimonio cultural sumergido. Realizado hasta el momento de manera experimental, se están estudiando formas para su puesta en marcha permanentemente.

Milagrosa Jiménez Melero, Carlos Alonso Villalobos, CAS-IAPH 